\title{
Long-term outcomes of limbal relaxing incisions during cataract surgery: aberrometric analysis
}

\author{
This article was published in the following Dove Press journal: \\ Clinical Ophthalmology \\ 31 August 2015 \\ Number of times this article has been viewed
}

\section{Gaspare Monaco \\ Antonio Scialdone}

Department of Ophthalmology, Ospedale Fatebenefratelli e Oftalmico, Milan, Italy
Correspondence: Gaspare Monaco

Oculistica I, Ospedale Fatebenefratelli e Oftalmico, Via Castelfidardo I5,

20121 Milan, Italy

Tel +3902 636/2262

Email gaspare.monaco@fbf.milano.it
Purpose: To compare the final changes in corneal wavefront aberration by limbal relaxing incisions (LRIs) after cataract surgery.

Methods: This prospective cumulative interventional nonrandomized case study included cataract and astigmatic patients undergoing LRIs and phaco with intraocular lens implantation. LRIs were planned using Donnenfeld nomogram. The root mean square of corneal wave aberration for total $Z(n, i)(1 \leq n \leq 8)$, astigmatism $Z(2, \pm 1)$, coma $Z(3-5-7, \pm 1)$, trefoil $Z(3-5-7, \pm 2)$, spherical Z $(4-6-8,0)$, and higher-order aberration (HOA) Z( $3 \leq \mathrm{n} \leq 8)$ was examined before and 3 years after surgery (optical path difference-Scan II [OPD-Scan II)]. Uncorrected distance visual acuity and best-corrected distance visual acuity (CDVA) for distance, keratometric cylinder, and variations in average corneal power were also analyzed.

Results: Sixty-four eyes of 48 patients were included in the study. Age ranged from 42 to 92 years (70.6 \pm 8.4 years). After LRIs, uncorrected distance visual acuity and best-corrected distance visual acuity improved statistically $(P<0.01)$. The keratometric cylinder value decreased by $40.1 \%$, but analysis of KP90 and KP135 polar values did not show any decrease that could be statistically confirmed $(P=0.22$ and $P=0.24$ ). No significant changes were detected in root mean square of total $(P=0.61)$ and HOAs $(P=0.13)$ aberrations. LRIs did not induce alteration in central corneal power confirming a 1:1 coupling ratio.

Conclusion: LRIs determined a nonsignificant alteration of corneal HOA. Therefore, LRIs can be still considered a qualitatively viable mean in those cases where toric intraocular lenses are contraindicated or not available. Yet, the authors raise the question of nonpersonalized nomograms, as in the present study, LRIs did not reach the preset target cylinder.

Keywords: astigmatism, ocular wavefront, intraocular lens, wavefront aberration

\section{Introduction}

At the time of cataract surgery, astigmatism can be corrected combining incisional techniques, such as limbal relaxing incisions (LRIs) with conventional intraocular lenses (IOLs), or directly implanting a toric IOL. Both methods present strengths and weaknesses. LRIs are a relatively safe and inexpensive procedure inducing low amount of irregularity on corneal topographies, as well as minor glare and patient discomfort. ${ }^{1-4}$ However, we know that LRIs are surgeon-dependent and result in some degree of variability and unpredictability, which causes an increase in higher-order aberrations (HOAs) and, ${ }^{5}$ occasionally, in dry eye and healing problems. ${ }^{6}$ On the other hand, toric IOLs are precise, predictable, and reliable, while requiring specialized surgical skills. ${ }^{7-9}$ Indeed, toric IOL effective correction of astigmatism relies on performing accurate keratometry and on the mastery of a perfect insertion technique, thus avoiding any postoperative (postop) rotation, even though rotations may be independently induced by postop capsular bag shrinkage. ${ }^{10}$ 
Although several studies report that toric IOLs have advantages in comparison to LRIs in terms of astigmatism correction, ${ }^{11-24}$ we wanted to assess the final changes in corneal wavefront aberration caused by an LRI after cataract surgery through direct comparison before and after surgery on a single patient. The main objective of this study was to determine whether conventional LRIs using a diamond knife have an impact on corneal HOA and therefore on visual optical quality.

\section{Materials and methods Patients}

This prospective, cumulative, interventional, nonrandomized, case study included astigmatic patients undergoing cataract surgery with IOL implantation between October 2011 and February 2012. An informed consent form in accordance with the Helsinki Declaration was obtained from each patient. The institutional review board and the ethics committee of Ospedale Fatebenefratelli e Oftalmico, Milan, Italy, approved the study. Inclusion criteria were patients with cataract and Lens Opacity Classification System III severity of NO1, C1, P1, or more; ${ }^{25}$ keratometric $(\mathrm{K})$ astigmatism greater than 0.5 diopters $(\mathrm{D})$; and no other ocular comorbidity that might influence visual outcome. Exclusion criteria were patients with active ocular diseases, significant level of corneal HOA exceeding $0.350 \mu \mathrm{m}$, using the Zernike polynomials from the topography map (OPDScan II; Nidek Co., Ltd., Gamagori, Japan), and a high irregular astigmatism index $(>0.54)$. Irregular astigmatism index is the result of average sum of interring area-corrected dioptric variations along every semimeridian for the whole analyzed surface and normalized by average corneal power (ACP) and the number of all measured points. It describes the short-range semimeridional fluctuation of power distribution and increases along with local irregular corneal astigmatism.

\section{Limbal relaxing incisions calculation}

Length and number of LRIs were calculated on a web site (http://www.lricalculator.com, last accessed February 25, 2012) in order to obtain the minimum value of residual astigmatism. This calculator employs Donnenfeld nomogram (DONO) and automatically takes into account the vector from the phaco incisions. The DONO is rated effective between 0.5 and $3 \mathrm{D}$ of astigmatism. The suggested length for an LRI is $90^{\circ}$ (3 clock hours). Each $90^{\circ} \mathrm{LRI}$ provides approximately $1.5 \mathrm{D}$ of correction. The phaco incision and the LRI should not overlap. $\mathrm{K}$ readings, surgically induced astigmatism (SIA), and tunnel location were required. K readings were simulated keratometry (SIM Ks) provided by corneal navigator, a function integrated into OPD-Scan II. SIM Ks values include curvature radii along the steepest and the flattest meridians crossing each other at right angles and corneal refractive powers based in a $3 \mathrm{~mm}$ zone centrally on an axial map. A SIA value of $0.20 \mathrm{D}$ and a temporal tunnel location was also introduced $\left(180^{\circ}\right.$ for right eyes and $0^{\circ}$ for left eyes). In case of a SIA cylinder of $0-0.5 \mathrm{D}$, the LRI calculator software suggests a $30^{\circ}$ phaco incision. The paracentesis is considered astigmatically neutral. In case of astigmatism lower than $0.5 \mathrm{D}$ (including SIA), the software automatically displays a message to avoid LRIs at all.

\section{Surgical technique}

All procedures were performed by the same surgeon (AS), under topical anesthesia. Preoperatively and before pupil dilatation, slit-lamp-marking technique was performed with patient sitting in upright position and staring at a distant target at head height using the contralateral eye. The finest slit allowed by the slit-lamp was centered on the corneal apex and rotated to the central axis of the planned incisions, using the slit rotation index. The tip of a 30 gauge needle was used to mark limbus at both ends. The length of LRIs was then marked by a fine-tipped marking pen at the beginning of surgery, using a Mendez ring (Martel Inc., Dover, DE, USA). Based on the procedure described by Langerman, ${ }^{26}$ after proceeding to the operating room and under the operating microscope, a vertical limbal relaxing wound was created with a guarded micrometer diamond blade (Meyco, Biel-Bienne, Switzerland) by making a $0.5 \mathrm{~mm}$ groove inside limbus in clear cornea. The incision depth was standardized at $600 \mu \mathrm{m}$. After making a single or paired incision as indicated by the nomogram, a $2.2 \mathrm{~mm}$ sutureless temporal clear corneal tunnel was created, avoiding overlapping with LRIs. Coaxial phacoemulsification was subsequently performed with AcrySof IQ SN60WF (Alcon Laboratories, Inc., Fort Worth, TX, USA) implantation. In all cases, the goal was emmetropia. As LRIs approximately have a 1:1 coupling ratio, no change in IOL power was needed. The coupling ratio describes the amount of flattening induced in the incised meridian referring to the steepening occurring $90^{\circ}$ away. In case of LRIs, negligible change in sphero-equivalent occurs, thus avoiding any adjusting of IOL power. ${ }^{13}$

\section{Preoperative (preop) and postop examinations}

All patients underwent full ophthalmologic examination preoperatively and postoperatively (after 3 years), including refractive status, uncorrected distance visual acuity (UDVA) and best-corrected distance visual acuities (CDVAs) for distance, slit-lamp examination, tonometry, and funduscopy. 
Visual data were obtained using logMAR units. Additionally, corneal topography and aberrometry (OPD-Scan II), endothelial cell count (Non-Con Robo SP 6000, Konan Medical Inc., Irvine, CA, USA), corneal thickness (Pentacam ${ }^{\circledR} \mathrm{HR}$, OCULUS, Inc., Lynnwood, WA, USA), biometry (Lenstar LS900 ${ }^{\circledR}$, Haag-Streit AG, Koeniz, Switzerland), and macular optical coherence tomography (HRA2, Heidelberg Engineering $\mathrm{GmbH}$, Heidelberg, Germany) were performed (when preoperatively feasible).

Wavefront and topographic assessments were performed using OPD-Scan II, which converts dynamic skiascopy data points (up to 1,440) into wavefront values, using Zernike polynomials up to eighth order. The OPD-Scan II measures the whole eye wavefront aberration and, through the placidobased corneal topography adoption, directly calculates corneal wavefront aberration. OPD-Scan II has demonstrated similar reproducibility but lower interobserver variability when compared to other wavefront aberrometers. ${ }^{27,28}$

All tests were performed by an independent observer (GM). Data analysis was performed by one of the authors (GM), upon completion of the data collection.

\section{Outcome measures}

On a 3-year follow-up visit, the following changes in corneal parameters were considered: 1) root mean square (RMS) of wave aberration for total $\mathrm{Z}(\mathrm{n}, \mathrm{i})(1 \leq \mathrm{n} \leq 8)$, astigmatism $Z(2, \pm 1)$, coma $Z(3-5-7, \pm 1)$, trefoil $Z(3-5-7, \pm 2)$, spherical $\mathrm{Z}(4-6-8,0)$, and HOA $\mathrm{Z}(3 \leq \mathrm{n} \leq 8)$ with a $4.0 \mathrm{~mm}$ aperture diameter; 2) SIM Ks; 3) keratometric cylinder (CYL); 4) difference between pre-calculated (expected) and postop (obtained) CYL; 5) ACP (ACP is an area-corrected average of corneal power ahead of the entrance pupil and generally equal to $\mathrm{K}$ spherical equivalent, except for decentered refractive surgical procedures); 6) surface regularity index (SRI is correlated to potential visual acuity and measures local fluctuations in central corneal power); and 7) standard deviation of corneal power (SDP is calculated from distribution of all corneal powers in a videokeratograph; it is often elevated in all situations involving a wide range of powers occurring in measured topography). Postop UDVA and CDVA were also reported. Since preop and postop CYL presents different axes, comparison between preop versus postop, and expected versus obtained values was carried out using polar value analysis. $^{29}$

\section{Statistical analysis}

Statistical analysis was performed using SPSS Windows software (version 15.0, SPSS Inc., Chicago, IL, USA). A sample size was determined from the data collected by the authors in previous studies. Based on such information, a 95\% confidence level, a $\pm 20 \%$ precision and a $P<0.05$ variability, the number of eyes necessary to detect the difference between preop and postop values was 64 . Normality of all data samples was assessed using Kolmogorov-Smirnov test. For parametric analysis, a Student's $t$-test for paired data was performed for comparisons between preop and postop examinations or expected versus obtained data. Whenever parametric analysis was not feasible, Wilcoxon rank-sum test was performed to assess the significance of difference between preop and postop conditions, or expected versus obtained data. The same level of significance was used for all statistical test $(P<0.05)$.

\section{Results}

Out of 55 patients recruited, seven were excluded on account of: central retinal vein occlusion (one patient), concomitant cardiovascular diseases (three patients), noshow on follow-up visits (three patients). Sixty-four eyes of 48 patients ( 27 female and 21 male) were included in this study. Age ranged from 42 to 92 years (70.6 \pm 8.4 years). No perioperative and postop complications occurred.

Table 1 shows the evolution of corneal aberrations after surgery. At 3 years, no statistical difference was found in

Table I Corneal wavefront aberrations with a $4.0 \mathrm{~mm}$ aperture diameter over time. Corresponding two-tailed $P$-values for the comparison between the visits are shown for each parameter

\begin{tabular}{llll}
\hline Parameter & Mean \pm SD $($ range $)$ & Difference between \\
\cline { 3 - 4 } RMS & Preop visit $(\mu \mathrm{m})$ & 3 year postop visit $(\mu \mathrm{m})$ & 0.61 \\
Total & $1.10 \pm 1.63(0.4-3.0)$ & $0.92 \pm 1.30(0.3-2.8)$ & 0.10 \\
Astigmatism & $0.96 \pm 1.05(0.3-2.1)$ & $0.65 \pm 0.51(0.1-2.1)$ & 0.83 \\
Coma & $0.12 \pm 0.34(0.0-0.6)$ & $0.13 \pm 0.35(0.0-0.6)$ & 0.004 \\
Trefoil & $0.12 \pm 0.28(0.0-0.5)$ & $0.16 \pm 0.13(0.0-0.3)$ & 0.98 \\
Spherical aberration & $0.05 \pm 0.03(0.0-0.1)$ & $0.06 \pm 0.01(0.0-0.2)$ & 0.13 \\
HOA & $0.21 \pm 0.39(0.0-0.8)$ & $0.26 \pm 0.35(0.0-0.7)$ & \\
\hline
\end{tabular}

Note: *Wilcoxon rank-sum test.

Abbreviations: RMS, root mean square; preop, preoperative; postop, postoperative; HOA, higher-order aberration. 
terms of RMS of total aberrations $\mathrm{Z}(\mathrm{n}, \mathrm{i})(1 \leq \mathrm{n} \leq 8)(P=0.61)$ which decreased mainly due to reduction in astigmatism $\mathrm{Z}(2, \pm 1)(P=0.10)$. No significant changes were found in the RMS value of HOA $\mathrm{Z}(3 \leq \mathrm{n} \leq 8)(P=0.13)$ except for the trefoil $Z(3, \pm 2)$, which showed a significant increase $(P=0.004)$.

In Table 2, the visual and refractive data are reported. UDVA and CDVA improved statistically $(P<0.01)$. CYL value decreased by $40.1 \%$. Analysis of KP90 and KP135 polar values did not show a statistical decrease $(P=0.22$ and $P=0.24$, Wilcoxon rank-sum test). The target CYL was not reached, as confirmed by the analysis of the difference between expected and obtained CYL $(P<0.01$, Wilcoxon rank-sum test).

LRIs did not induce alteration and fluctuations in central corneal power (ACP, SDP, and SRI).

\section{Discussion}

At the time of cataract surgery, astigmatism can be corrected using incisional techniques, such as LRIs. Yet, little is known about the outcomes of corneal aberrations after surgery.

The aim of this study was to assess long-term changes induced by LRIs on HOA and corneal optical quality.

Three years after procedure, as shown in Table 1, no significant differences were found in terms of the RMS value of HOA between preop and postcorneal aberrations (Figure 1). Such a result contrasts sharply with the conclusions of a previous report by Montés-Micó et al where the authors found that astigmatic keratotomy (AK) increased HOA, both coma-like and spherical-like, in a population of patients treated for high myopic astigmatism. ${ }^{5}$ This could confirm that LRIs are more conservative than astigmatic keratotomy in terms of aberrations, however, probably less effective. Indeed, in our study, only one value showed a significant increase: the trefoil. This figure could relate to the findings of Denoyer et al showing how corneal trefoil increases along with size of incision during cataract surgery. ${ }^{30}$ Finally, it can be assumed that if an incisional procedure, such as LRIs, is added during phacoemulsification surgery, third-order aberrations in cornea are only partially affected. If the unaltered indices of corneal irregularities - such as SRI and SDP - are taken into account, it may be assumed that LRIs can be considered safe, thus not causing significant irregularities in corneal morphology.

Total wavefront aberrations decreased mainly due to reduced astigmatism (Figure 2). The result has been confirmed by refractive data, as shown in Table 2. CYL value decreased to a mean value of $40.1 \%$, comparable to the one reported in literature by several authors. Budak et al reported an absolute decrease in mean astigmatism by $44 \%,{ }^{31}$ Bayramlar et al 52\%, ${ }^{32}$ Kaufmann et al 25\%, ${ }^{33}$ Carvalho et al $50 \%,{ }^{34}$ and Kim et al 32\%. ${ }^{35}$ However, analysis of KP90 and KP135 polar values did not show, in our study, a significant reduction. Target postop CYL was not reached, as confirmed by the analysis of the difference between expected and obtained CYL. Only Sharma et al reported positive results using DONO. ${ }^{36}$ We think that the nomograms proposed in the literature, including the one we used, are not able to thoroughly account for and correct all the tissue factors influencing the results. Personalized nomograms probably are not a viable solution because they are not exact and are far too dependent on the surgeon's specific medical expertise, thus proving counterproductive. These limitations should be improved by femtosecond laser, even if recent reports disagree, probably because the technique involves the same biologic aspects. ${ }^{37,38}$

Table 2 Change in visual and refractive data over time. Corresponding two-tailed $P$-values for the comparison between the visits are shown for each parameter

\begin{tabular}{|c|c|c|c|}
\hline \multirow[t]{2}{*}{ Parameter } & \multicolumn{2}{|l|}{ Mean \pm SD (range) } & \multirow{2}{*}{$\begin{array}{l}\text { Difference between } \\
\text { visits ( } P \text {-value) }\end{array}$} \\
\hline & Preop visit & 3 year postop visit & \\
\hline UDVA (LogMAR) & $0.70 \pm 0.19(0.2$ to 1.0$)$ & $0.12 \pm 0.01$ (0.0 to 0.4$)$ & $0.00 *$ \\
\hline CDVA (LogMAR) & $0.5 \mathrm{I} \pm 0.24(0.3$ to $\mathrm{I} .0)$ & $0.02 \pm 0.00(0.0$ to 0.1$)$ & $0.00 *$ \\
\hline CYL (D) & $2.22 \pm 2.6 \mathrm{I}(0.6$ to 4.9$)$ & $1.33 \pm 2.03$ (0.3 to 4.8$)$ & Not applicable \\
\hline KP90 (D) & $-0.33 \pm 1.90(-3.3$ to 2.2$)$ & $0.15 \pm 1.91$ ( -1.2 to 2.8$)$ & $0.22 *$ \\
\hline KPI35 (D) & $-0.37 \pm 2.65$ ( -4.6 to 2.9$)$ & $0.35 \pm 1.39(-1.3$ to 3.9$)$ & $0.24 *$ \\
\hline SRI & $0.70 \pm 0.45(0.2$ to 1.3$)$ & $0.60 \pm 0.49(0.1$ to 1.4$)$ & $0.29 *$ \\
\hline SDP & $1.14 \pm 1.32$ (0.6 to 2.6$)$ & $1.03 \pm 1.23(0.5$ to 2.4$)$ & $0.86^{*}$ \\
\hline $\mathrm{ACP}(\mathrm{D})$ & $43.7 I \pm 2.80(40.2$ to 47.2$)$ & $43.49 \pm 3.26(40.1$ to 47.7$)$ & $0.45^{*}$ \\
\hline
\end{tabular}

Note: *Wilcoxon rank-sum test.

Abbreviations: preop, preoperative; postop, postoperative; UDVA, uncorrected distance visual acuity; CDVA, best-corrected distance visual acuity; CYL, keratometric cylinder; D, diopters; KP90, polar value along $90^{\circ}$ meridian; KPI35, polar value along $135^{\circ}$ meridian; SRI, surface regularity index; SDP, standard deviation of corneal power; ACP, average corneal power. 

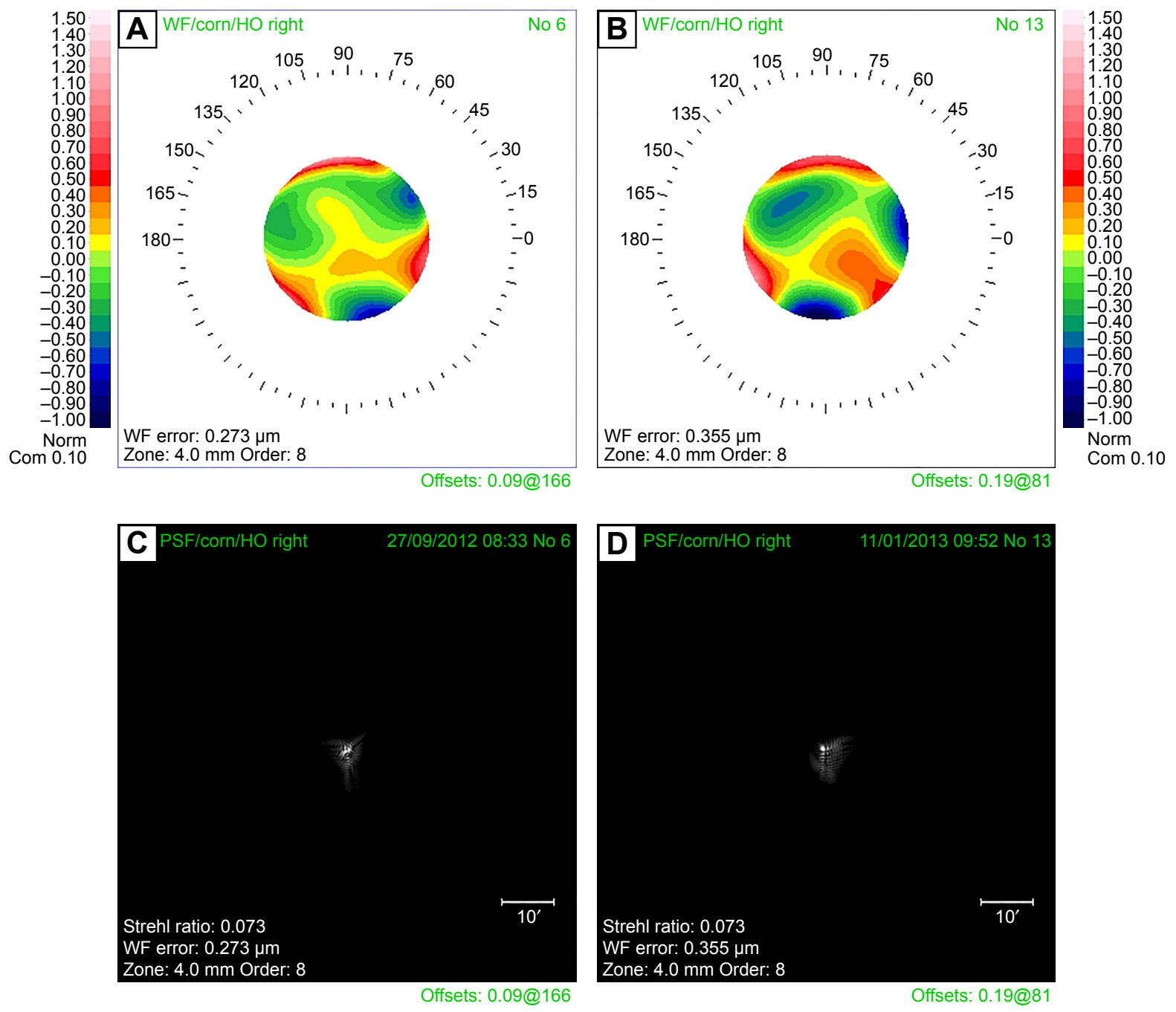

Cornea index: $n=1.3375$ (Ax, Ins), n=1.3760 (Ref, TRef, I.OPD) Qm: $6.0 \mathrm{~mm} \lambda: 587.6 \mathrm{~nm}$

Mapset: LRI2

Figure I Trend of higher-order aberrations over time.

Notes: Corneal wavefront (WF) maps of higher-order aberrations (HOA) of one eye preoperatively (A) and 3 years after (B) limbal relaxing incisions (LRIs) and intraocular lens implantation. Correlated point spread function (PSF) maps obtained with optical path difference (OPD)-Scan II of one eye preoperatively (C) and 3 years after (D) surgery. In this patient wavefront error provided by HOA increased slightly over time determining an unchanged PSF.

Abbreviations: corn, cornea; HO, higher-order; WF, wavefront.

Average central corneal power was not significantly modified by LRIs, thus confirming the value of the coupling ratio of approximately $1: 1$ previously published. To our knowledge, this is the first report using ACP to confirm such a coupling ratio. Previously, Lindstrom found a 1:1 coupling ratio when a straight $3 \mathrm{~mm}$ keratotomy or a $45^{\circ}-90^{\circ}$ arcuate keratotomy incision is performed, thus showing that coupling ratio depends on the length, location, and depth of incision. ${ }^{13}$ Thornton stated that a true 1:1 coupling ratio can only occur when corneal incisions act as an added tissue but at the same time, corneal circumference is not changed; the latter result is achieved only in case of short, concentric, and arcuate incisions. ${ }^{39}$
The authors are aware that the present study is limited by data resulting from a 3-year assessment. This means that they cannot rule out the possibility that part of the LRI effect could be due to surgical regression. Yet, the aim of this study was to assess the final outcome, not the evolution in time.

\section{Conclusion}

Our study demonstrated that LRIs during cataract surgery do not induce significant changes in corneal HOA. For this reason, though the variability of refractive correction is still a major drawback, LRIs can still be considered a safe and viable means to correct astigmatism in those cases where toric IOLs are contraindicated or not available. 

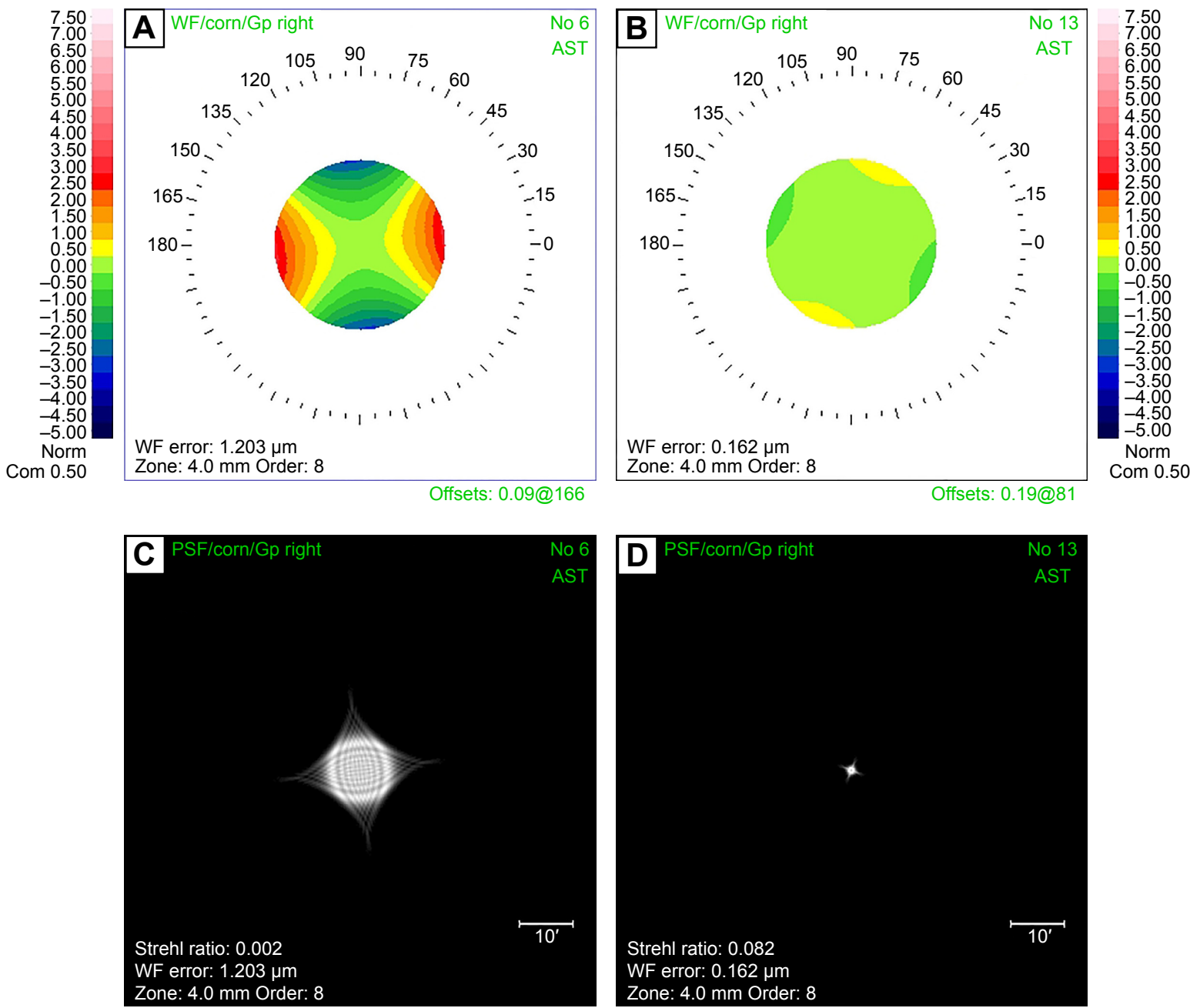

Offsets: $0.09 @ 166$

Cornea index: $\mathrm{n}=1.3375$ (Ax, Ins), $\mathrm{n}=1.3760$ (Ref, TRef, I.OPD) Qm: $6.0 \mathrm{~mm} \lambda: 587.6 \mathrm{~nm}$ Mapset: LRI1

Figure 2 Trend of astigmatism aberration over time.

Notes: Corneal wavefront (WF) maps of astigmatism of one eye preoperatively (A) and 3 years after (B) limbal relaxing incisions (LRIs) and intraocular lens implantation. Correlated point spread function (PSF) maps obtained with optical path difference (OPD)-Scan II of one eye preoperatively (C) and 3 years after (D) surgery. The PSF displays the simulated view of how a point source of light like a star at infinity looks to a patient. The minor deformation of the light point source, the good Strehl ratio, and the relatively low level of wavefront error demonstrate the good quality of vision. In this patient wavefront error provided by astigmatism decreased over time determining a better PSF.

Abbreviations: corn, cornea; WF, wavefront.

\section{Disclosure}

The authors report no conflicts of interest in this work.

\section{References}

1. Nichamin LD. Astigmatism control. Ophthalmol Clin North Am. 2006; 19(4):485-493.

2. Gills JP, Van Der Karr M, Cherchio M. Combined toric intraocular lens implantation and relaxing incisions to reduce high pre-existing astigmatism. J Cataract Refract Surg. 2002;28:1585-1588.

3. Budak K, Friedman NJ, Koch DD. Limbal relaxing incisions with cataract surgery. J Cataract Refract Surg. 1998;24:503-508.

4. Müller-Jensen K, Fischer P, Siepe U. Limbal relaxing incisions to correct astigmatism in clear corneal cataract surgery. J Refract Surg. 1999; 15:586-589.
5. Montés-Micó R, Munoz G, Albarran-Diego C, Rodriguez-Galietero A, Aliò JL. Corneal aberrations after astigmatic keratotomy combined with laser in situ keratomileusis. J Cataract Refract Surg. 2004;30: $1418-1424$

6. Nichamin LD. Changing approach to astigmatism management during phacoemulsification: Peripheral arcuate astigmatic relaxing incisions. Presented at: The Annual Meeting of the American Society of Cataract and Refractive Surgery; 2000; Boston, MA.

7. Miyake T, Kamiya K, Amano R, Iida Y, Tsunehiro S, Shimizu K. Longterm clinical outcomes of toric intraocular lens implantation in cataract cases with preexisting astigmatism. J Cataract Refract Surg. 2014; 40:1654-1660.

8. Scialdone A, Raimondi G, Monaco G. In vivo assessment of higher-order aberrations after Acrysof toric intraocular lens implantation: a comparative study. Eur J Ophthalmol. 2012;22(4):531-540. 
9. Hayashi K, kondo H, Yoshida M, Manabe S, Hirata A. Higher-order aberrations and visual function in pseudophakic eyes with a toric intraocular lens. J Cataract Refract Surg. 2012;38:1156-1165.

10. Grabow HB. Early results with foldable toric IOL implantation. Eur J Implant Refract Surg. 1994;6:177-178.

11. Kohnen T, Koch DD. Methods to control astigmatism in cataract surgery. Curr Opin Ophthalmol. 1996;7(1):75-80.

12. Buzard K, Haight D, Troutman R. Ruiz procedure for postkeratoplasty astigmatism. J Refract Surg. 1987;3:40-45.

13. Lindstrom RL. The surgical correction of astigmatism: a clinician's perspective. Refract Corneal Surg. 1990;6(6):441-454.

14. Tadros A, Habib M, Tejwani D, Von Lany H, Thomas P. Opposite clear corneal incisions on the steep meridian in phacoemulsification: early effects on the cornea. J Cataract Refract Surg. 2004;30:414-417.

15. Gills JP, Gayton JL. Cataract Surgery: The State of the Art. Thorofare, NJ: Slack Inc; 1998:53-66.

16. Kershner RM. Surgical Treatment of Astigmatism. Thorofare, NJ: Slack Inc; 1994:143-155.

17. Grabow HB. Refractive Keratotomy for Cataract Surgery and the Correction of Astigmatism. Thorofare, NJ: Slack Inc; 1994:79-115.

18. Kershner RM. Toric lenses for correcting astigmatism in 130 eyes. Ophthalmology. 2000;107:1776-1782.

19. Maloney WF, Sanders DR, Pearcy DE. Astigmatic keratotomy to correct preexisting astigmatism in cataract patients. J Cataract Refract Surg. 1990;16:297-304

20. Osher RH. Contemporary Refractive Surgery Ophthalmology Clinics of North America. Philadelphia, PA: W.B. Saunders. 1992:717-725.

21. Buzard KA, Laranjeira E, Fundingsland BR. Clinical results of arcuate incisions to correct astigmatism. J Cataract Refract Surg. 1996;22 436-440.

22. Gills JP, Fenzl RE. Analysis of astigmatic keratotomy with a 5.0-mm optical clear zone. Am J Ophthalmol. 1996;121:731-732.

23. Nichamin LD, Wallace RB. Refractive Cataract Surgery and Multifocal IOLs. Thorofare, NJ: Slack Inc; 2001:167-172.

24. Shepherd JR. Correction of preexisting astigmatism at the time of small incision cataract surgery. J Cataract Refract Surg. 1989;15:55-57.

25. Chylack LT Jr, Wolfe JK, Singer DM, et al. The lens opacities classification system III. The longitudinal study of Cataract Study Group. Arch Ophthalmol. 1993;111(6):831-836.

26. Langerman DW. Architectural design of a self-sealing corneal tunnel, single-hinge incision. J Cataract Refract Surg. 1994;20:84-88.
27. Bartsch DU, Bessho K, Gomez L, Freeman WR. Comparison of laser ray-tracing and skiascopic ocular wavefront-sensing devices. Eye. 2008; 22(11):1384-1390.

28. Visser N, Berendschot TT, Verbakel F, Tan AN, de Brabander J, Nuijts RM. Evaluation of the comparability and repeatability of four wavefront aberrometers. Invest Ophthalmol Vis Sci. 2011;52(3):1302-1311.

29. Naeser K, Hjortdal JO. Multivariate analysis of refractive data: mathematics and statistic of spherocylinders. J Cataract Refract Surg. 2001; 27:129-142.

30. Denoyer A, Ricaud X, Van Went C, Labbé A, Baudouin C. Influence of corneal biomechanical properties on surgically induced astigmatism in cataract surgery. J Cataract Refract Surg. 2013;39(8):1204-1210.

31. Budak K, Y1lmaz G, Aslan BS, Duman S. Limbal relaxing incisions in congenital astigmatism: 6 month follow-up. J Cataract Refract Surg. 2001;27:715-719.

32. Bayramlar HH, Dağlioğlu MC, Borazan M. Limbal relaxing incisions for primary mixed astigmatism and mixed astigmatism after cataract surgery. J Cataract Refract Surg. 2003;29:723-728.

33. Kaufmann C, Peter J, Ooi K, Phipps S, Cooper P, Goggin M. Limbal relaxing incisions versus on-axis incisions to reduce corneal astigmatism at the time of cataract surgery. J Cataract Refract Surg. 2005; 31:2261-2265

34. Carvalho MJ, Suzuki SH, Freitas LL, Branco BC, Schor P, Lima AL. Limbal relaxing incisions to correct corneal astigmatism during phacoemulsification. J Refract Surg. 2007;23:499-504.

35. Kim DH, Wee WR, Lee JH, Kim MK. The short term effects of a single limbal relaxing incision combined with clear corneal incision. Korean J Ophthalmol. 2010;24(2):78-82.

36. Sharma BR, Kumar A. Preliminary experiences with limbal relaxing incision for treatment of astigmatism during phacoemulslfication. Nepal J Ophthalmol. 2009;1(2):90-94.

37. Venter J, Blumenfeld R, Schallhorn S, Pelouskova M. Non-penetrating femtosecond laser astigmatic keratotomy in patients with mixed astigmatism after previous refractive surgery. J Refract Surg. 2013; 29(3):180-186.

38. Chan TC, Cheng GP, Wang Z, Tham CC, Woo VC, Jhanji V. Vector analysis of cornea astigmatism after combined femtosecond-assisted phacoemulsification and arcuate keratotomy. Am JOphthalmol. 2015;160(2): 250-255.

39. Thornton SP. Sutureless Cataract Surgery. Thorofare, NJ: Slack Inc; 1992:123-143.
Clinical Ophthalmology

\section{Publish your work in this journal}

Clinical Ophthalmology is an international, peer-reviewed journal covering all subspecialties within ophthalmology. Key topics include: Optometry; Visual science; Pharmacology and drug therapy in eye diseases; Basic Sciences; Primary and Secondary eye care; Patient Safety and Quality of Care Improvements. This journal is indexed on Submit your manuscript here: http://www.dovepress.com/clinical-ophthalmology-journa

\section{Dovepress}

PubMed Central and CAS, and is the official journal of The Society of Clinical Ophthalmology (SCO). The manuscript management system is completely online and includes a very quick and fair peer-review system, which is all easy to use. Visit http://www.dovepress.com/ testimonials.php to read real quotes from published authors. 